\title{
|||||||| $\begin{aligned} & \text { Journal of Technology } \\ & \text { Management \& Innovation }\end{aligned}$
}

Received September 18, 2008 / Accepted November 24, 2008

J.Technol. Manag. Innov. 2008,Volume 3, Issue 4

\section{Cooperação Internacional para o Desenvolvimento em Ciência e Tecnologia:A Participação Brasileira na Organização Européia para Pesquisa Nuclear (CERN)*}

Rafael Pinto Duarte (I)

\begin{abstract}
This work proposes a different approach of International Cooperation on the Brazilian scientific and technological (S\&T) development process, based on the case of the cooperation among Brazil and the European Organization for Nuclear Research (CERN). The studies lead to a suggestion of a new strategic approach of a system beginning starting at activities of international S\&T interchange and collaborations as initial stage that lead to International Cooperation, seen as the only one capable of directly create S\&T development. The case of the Brazilian activities at CERN shows that International Cooperation generates S\&T development only with long term assured financial and institutional arrangements between Universities and Industries, supported by government policies and programs. The results point to the assumption that International Cooperation is an essential element for elaboration and execution of public policies that aim national development on science and technology. .
\end{abstract}

Keywords: International Cooperation; Science and Technology; Development; High Energy Physics; European Organization for Nuclear Research (CERN).

\section{Resumo}

Este trabalho propõe uma abordagem diferente da Cooperação Internacional no processo de desenvolvimento científico e tecnológico brasileiro, tendo como base a cooperação entre o Brasil e a Organização Européia para Pesquisa Nuclear (CERN). Os estudos levam a uma visão estratégica de um ciclo que envolve intercâmbio e colaborações científicas internacionais como etapas iniciais que levam à Cooperação Internacional $(\mathrm{Cl})$, esta última verdadeiramente capaz de gerar desenvolvimento científico. $\mathrm{O}$ estudo da participação brasileira no CERN mostra que a $\mathrm{Cl}$ só gera desenvolvimento científico se contar com a participação do Estado para garantir investimentos e apoio institucional aos cientistas brasileiros no longo prazo.Assim a $\mathrm{Cl}$ torna-se elemento indispensável para a elaboração e execução de políticas públicas que vislumbrem o desenvolvimento científico e tecnológico nacional.

Palavras-chave: Cooperação Internacional; Ciência e Tecnologia; Desenvolvimento; Física de Altas Energias; Organização Européia para Pesquisa Nuclear (CERN)

\footnotetext{
* (Trata-se de um resumo da Dissertação de Mestrado "O Papel da Cooperação Internacional no Desenvolvimento Científico Brasileiro: o Caso do Acordo entre o Brasil e a Organização Européia para Pesquisa Nuclear", defendida em março de 2008 no Centro de Desenvolvimento Sustentável da Universidade de Brasília - CDS/UnB

(I) Mestre em Desenvolvimento Sustentável - Universidade de Brasília, Bacharel em Relações Internacionais pela Universidade Católica de Brasília e professor do Curso de Relações Internacionais do Centro Universitário do Distrito Federal - UDF - Brasil
} 


\section{Introdução}

Este trabalho consiste numa proposta do papel que a Cooperação Internacional pode assumir no âmbito das políticas públicas para o desenvolvimento em Ciência e Tecnologia, seja para otimizar os recursos orçamentários, alavancar a formação e capacitação de recursos humanos ou transferir e adaptar tecnologias para o Brasil.

A importância da Organização Européia para Pesquisa Nuclear (CERN) para a humanidade assume diversos domínios como: idealismo, relações humanas, colaboração entre países, planificação científica e tecnológica, formação de jovens e relações da ciência básica com a indústria (SALMERON, 2004, p. 4). $O$ seu sucesso como "maior laboratório do mundo em pesquisa fundamental e, por conseqüência, da Física mundial" (idem, p.l.) contribuiu para o desenvolvimento da Física Experimental de Altas Energias (FAE)' como campo do conhecimento de grande influência no século $X X$, de acordo com artigo elaborado pelo Centro Brasileiro de Pesquisas Físicas (CBPF):

A descoberta dos quanta, anunciada no alvorecer do século, levou à invenção do transistor e do circuito integrado, elementos essenciais da era da informação, à invenção do laser e da técnica de ressonância magnética nuclear, à descoberta da supercondutividade, à manufatura de novos materiais utilizados na Medicina, em dispositivos eletrônicos, em viagens espaciais. A energia nuclear teve importantes repercussões econômicas, políticas, científicas e medicinais. (CBPF, 2002, p. I5)

Esse trecho revela de maneira sucinta o impacto do desenvolvimento da Física, que não se restringiu apenas a essa área, tendo seus frutos colhidos por toda a comunidade científica internacional e também pela sociedade civil de um modo geral.

O Brasil, contudo, ainda não dispõe da estrutura necessária para atender à demanda da pesquisa científica de última geração em $\mathrm{FAE}$, que compreende grandes aceleradores de partículas, que requerem níveis energia da ordem de bilhões de volts, e laboratórios com estrutura de última geração (energia, recursos computacionais, sistema de transmissão e armazenamento de dados, laboratórios para estudos de aplicações tecnológicas). Para que o desenvolvimento dessa área seja possível no País, a comunidade científica brasileira depende fundamentalmente da Cooperação Internacional com grandes centros de pesquisa in- ternacionais, como o CERN, para se manter na vanguarda do conhecimento. Tal posição pode permitir ainda transferir todos os seus avanços científicos e tecnológicos para a sociedade brasileira e contribuir para o desenvolvimento nacional, aspiração que só é possível com apoio fundamental do Governo.

No que se refere à cooperação Brasil-CERN, o país possui mais de uma dezena de pesquisadores vinculados a universidades ou centros de pesquisa nacionais de alto nível técnico-científico que participam ativamente de diversos experimentos em desenvolvimento no CERN, segundo dados do Conselho Nacional de Desenvolvimento Científico e Tecnológico (CNPq).As atividades dos pesquisadores brasileiros nessa Organização têm sido muito importantes para o desenvolvimento científico nacional, principalmente na área de $\mathrm{FAE}$, por conferir acesso a pesquisas na fronteira do conhecimento realizadas naquele Centro. Um exemplo da importância desta cooperação está na participação da indústria brasileira para a confecção de circuitos eletrônicos que compõem um experimento do CERN, com colaboração direta de cientistas brasileiros desde a sua construção, num exemplo de transferência de tecnologia direta do CERN para o Brasil por meio dos cientistas (DUARTE, 2004, p. 36-37).

Recentemente, a comunidade científica brasileira que trabalha com o CERN teve dificuldades para se seguir com determinadas pesquisas na área de FAE por depender significativamente do convencimento, por parte do governo, de que investir em grandes empreendimentos científicos internacionais significa um esforço amplo e de longo prazo, mas que podem trazer resultados de grande significância. A falta de apoio dessa magnitude à equipe brasileira resultou na demora de seis anos para renovar o acordo de cooperação internacional com o CERN, deixando pesquisadores brasileiros sem financiamento adequado para desenvolver atividades nos seus experimentos nem incentivos para a internalização de novas tecnologias que poderiam ser transferidas.

Por isso, o desafio para o Brasil é encadear a Cooperação Internacional em C\&T no eixo das políticas públicas de desenvolvimento em ciência, tecnologia e inovação de modo a garantir um apoio sólido à pesquisa em parceria com grupos e centros de pesquisa de ponta, tanto em termos de aparato institucional quanto aporte de recursos financeiros. Equacionar uma estratégia que envolva a $\mathrm{Cl}$ significa habilitar os cientistas brasileiros a participar das atividades que estão nas fronteiras

I A área de Física Experimental de Altas Energias - FAE, também chamada de Física de Partículas Elementares e Campos é o ramo da Física que tem por objetivo o estudo das quatro interações fundamentais da natureza (Gravitacional, Eletromagnética, Fraca e Forte) e seus elementos fundamentais, as partículas elementares. (SANTORO \& NOVAES, 2007) 
do conhecimento e dessa forma transferir seus avanços para Brasil e contribuir para a solução de problemas da sociedade nacional.

Com base no exposto, a pergunta que norteia esta dissertação é: qual o papel assumido pela Cooperação Internacional no processo de desenvolvimento científico e tecnológico brasileiro? O objetivo principal é analisar o papel da Cooperação Internacional em C\&T no desenvolvimento científico brasileiro, usando como estudo de caso a participação brasileira no CERN. Os objetivos específicos deste trabalho são: em primeiro lugar, servir de instrumento de referência para o entendimento da cooperação internacional em C\&T como estratégia para o desenvolvimento brasileiro em ciência, tecnologia e inovação. Em segundo, apresentar aspectos históricos, teóricos e analíticos da Cooperação Internacional em C\&T no Brasil, em razão da percepção de uma carência de estudos acadêmicos brasileiros sobre a Cooperação Internacional em C\&T como um conceito, teoria ou opção estratégica, principalmente no que diz respeito a sua relação com as políticas públicas de desenvolvimento científico e tecnológico, desde os seus atores até as vantagens que pode proporcionar ao País. Por último, pretende-se realizar um estudo de caso sobre a participação brasileira no CERN, organização científica tida como a detentora do principal modelo de cooperação internacional em C\&T pela comunidade internacional (SALMERON, 2004).

O caminho trilhado pelo presente trabalho para responder à pergunta e alcançar os objetivos irá apresentar os aspectos mais importantes da cooperação internacional em C\&T e sua aplicação a uma iniciativa junto à comunidade científica no campo da FAE, por este ser um ramo da ciência que contribuiu para os principais avanços da humanidade no século $X X$, como a energia nuclear, novos materiais, computação e a terapia do câncer, entre outros. Para tal, será feito o estudo de caso aqui relatado poderá indicar alternativas para a formulação de políticas públicas que vislumbrem a cooperação internacional em ciência e tecnologia.

O desenvolvimento deste trabalho obedeceu a duas etapas: primeiro, serão apresentados os conceitos da Cooperação Internacional em Ciência e Tecnologia e sua concepção como estratégia das políticas públicas de desenvolvimento em C\&T,e por fim, será relatada a participação brasileira nos seguintes experimentos do CERN: A Toroidal LHC Aparatus (ATLAS), Compact Múon Solenoid (CMS) e Large Hadron Collider beauty (LHCb), a contribuição dessas atividades para o desenvolvimento científico e tecnológico brasileiro e as perspectivas de inovações tecnológicas percebidas. Esses experimentos foram escolhidos por estarem em plena atividade de construção das estruturas ou operação em FAE e por contar com a participação de grupos cientíícos brasileiros.
Cabe informar que este estudo é um resumo de dissertação de mestrado realizada na Universidade de Brasília, no curso de Mestrado em Desenvolvimento Sustentável, área de concentração em Política e Gestão da Ciência e Tecnologia do Centro Ed Desenvolvimento Sustentável.

\section{Cooperacäo Internacional para o Desenvovimiento Científico e Tecnológico Brasileiro}

\section{I.I Reflexöes conceituais sobre a Cooperacäo Internacional voltada para o desenvolvimento en C\&T.}

No ensejo do desenvolvimento científico, uma análise a ser feita nesse trabalho é a diferença da cooperação para o intercâmbio e a colaboração internacional em ciência e tecnologia.

Cumpre, todavia, explicitar inicialmente o conceito de intercâmbio internacional, pelo qual se entende toda e qualquer atividade relacionada à interação ou simples troca de conhecimento, experiências de indivíduos ou comunidades de dois ou mais países e de alcance limitado, sem que haja necessariamente uma organização prévia para a sua implementação e o seu desenvolvimento. Um estudo realizado pela RAND Corporation, a pedido do Banco Mundial em 200I, exemplifica essa concepção:

Os cientistas com os quais conversamos citaram a especialização [individual] como razão principal para participar de colaborações, independente do fato de a participação de colegas de outros países for necessária ou uma mera escolha particular (...). Para catalisar o êxodo de cérebros de países em desenvolvimento, devem ser criadas condições para capacitar cientistas a conduzir os trabalhos por eles considerados significativos. Programas de intercâmbio internacional que vislumbrem múltiplas visitas de cientistas de países em desenvolvimento para reuniões e conduzir experimentos nos Estados Unidos são citados como bons modelos. Esses programas permitem a pesquisadores de países em desenvolvimento aumentarem seus níveis de conhecimento, expandir redes de profissionais e obter acesso a equipamentos e estruturas de pesquisa sem ter que deixar seus países de origem. (WAGNER, Caroline S et al, 200I, p. 55 - 83, tradução e grifo do autor).

O Livro Branco do Ministério da Ciência e Tecnologia também evidencia a limitação do alcance do Intercâmbio Internacional:

No passado, em geral, os acordos de cooperação entre nações quase não passavam de declaração de boas intenções, de criação de programas assistencialistas e de 
intercâmbio de pesquisadores - este último, sem dúvida, um instrumento útil, mas de alcance limitado, se desacompanhado de um amparo institucional”. (2002, p. 45 , grifo do autor).

Para o MCT, o intercâmbio internacional é o primeiro passo de qualquer iniciativa em C\&T que vislumbre possibilidades além da fronteira nacional. Contudo, é necessário haver um aparato institucional suficiente para transformar essa atividade, nascida quase ao mesmo tempo em que a ciência moderna, em desenvolvimento estrutural da C\&T no País.

Já a Colaboração Internacional é, segundo Beaver e Rosen (apud VELHO, 200 I, p. 59), uma experiência humana antiga como a própria ciência, observada pela participação conjunta de cientistas, comunidades ou instituições científicas de países diferentes, e resulta em empreendimentos científicos conjuntos com programas coordenados em torno de objetivos específicos. A RAND Corporation apresenta a Colaboração Científica Internacional como sendo:

(...) um processo crescente, com cientistas escolhendo individualmente trabalhar com colegas em função de curiosidades compartilhadas. Dessa forma, esse desenvolvimento de capacidade ocorreu, na maior parte, mais no nível individual dos cientistas do que permeando o campo de estudo ou uma organização (WAGNER, Caroline $S$ et al, 200I, p. 46, tradução e grifo do autor).

Fundamentalmente, Intercâmbio e Colaboração Internacional em C\&T têm um cunho individual, local ou regional, seja de um cientista, grupos ou instituições de pesquisa. A participação do Estado é irrelevante para que elas ocorram e se desenvolvam. Podem ser citados como exemplos para ambos os casos a troca de experiências científicas no exterior, que complementam pesquisas e agregam conhecimento para a publicação de artigos com participação de múltiplos autores e a operação conjunta em grandes empreendimentos e estruturas científicas nacionais.

Já a Cooperação Internacional $(\mathrm{Cl})$ em C\&T é definida pela Organização das Nações Unidas para a Educação, Ciência e Cultura (UNESCO) como "todo e qualquer compartilhamento de conhecimento entre dois ou mais cidadãos de diferentes nações, inserido em um contexto de convenções mutuamente aceitáveis, que possibilitem o intercâmbio desse conhecimento" (LIPSETT, HOLBROOK, apud MORGANTTI, 2005, p.23, grifo do autor). Essas convenções são os acordos internacionais de cooperação científica e tecnológica e os memorandos de entendimentos (MOU), que permitem o apoio institucional dos Estados para realização de projetos de pesquisa em parceria, podendo ou não compreender laboratórios internacionais de pesquisa.
O trecho grifado remete à concepção que pauta a abordagem da cooperação científica e tecnológica internacional voltada ao desenvolvimento científico e tecnológico: um esforço organizado, envolvendo dois ou mais países, com vistas ao desenvolvimento de determinadas atividades que vislumbrem o intercâmbio de conhecimento, métodos e processos científicos, contemplando inclusive a ocorrência de transferência de tecnologia para geração de inovações tecnológicas.

A principal diferença da Cooperação para o Intercâmbio e a Colaboração Internacional em C\&T é que a $\mathrm{Cl}$ conta com a presença indispensável do Estado para garantir ações de incentivo e apoio institucional e financeiro ao desenvolvimento da comunidade cientifica nacional e de proteção à propriedade intelectual gerada por novos conhecimentos adquiridos. $O$ Estado também é fundamental para encadear as novas descobertas científicas ao sistema de geração e transferência de tecnologias e inovações para a sociedade, normalmente chamado de Sistema Nacional de Ciência,Tecnologia e Inovação. Já o intercâmbio e a colaboração internacional estão circunscritos ao interesse individual ou de um grupo específico de cientistas, que não prevêem responsabilidades sobre as externalidades dos seus avanços para outros grupos, áreas do conhecimento ou setores da sociedade. Os acordos firmados entre comunidades ou instituições científicas são feitos sem qualquer participação dos Estados, não havendo condições de se estabelecerem grandes experimentos científicos como o projeto Genoma ou a Estação Espacial Internacional, por exemplo, pois tais atividades requerem investimentos da ordem de centenas de milhões de dólares, que não podem ser realizados por agentes econômicos privados isoladamente.

Como característica principal, a Cooperação Científica e Tecnológica Internacional se apóia em três pilares fundamentais: os cientistas, o conhecimento e o Estado. Os cientistas contribuem com a curiosidade e a capacidade de gerar e disseminar o conhecimento em C\&T. Esse conhecimento se torna um alicerce da $\mathrm{Cl}$ no momento em que assume um caráter específico, não-universal, além de ser o objeto a ser trabalhado pelos homens da ciência e, ao mesmo tempo, objetivo de uma proposta de Estado para solucionar problemas que se apresentam ao seu desenvolvimento. Por sua vez, cabe ao Estado garantir o aparato institucional e o aporte financeiro, público ou privado, para promover a troca de recursos humanos, conhecimento e experiências para, somados os esforços, buscar o desenvolvimento em ciência e tecnologia mais amplo, rápido e consistente, garantindo a repartição das novas descobertas entre todos os que nelas investiram, assim como o desenvolvimento delas derivado.

Tendo o desenvolvimento científico e tecnológico como objetivo é possível estabelecer uma relação entre os três conceitos. Intercâmbio e Colaboração internacional assumem um papel 
intermediário que garante, principalmente, o acesso e participação da comunidade científica nacional às atividades de P\&D mais avançadas. Uma vez estabelecido o acesso, cabe ao Estado promover a integração de cientistas nacionais de modo a transferir o conhecimento de fronteira desenvolvido nos principais centros de pesquisa mundiais e, de acordo com a excelência de cada área, adaptá-lo às suas necessidades.

Como exemplo de Cooperação Internacional em C\&T que seguem esse princípio pode ser citado o programa Genoma, que reúne como pilares o conhecimento sobre o genoma dos seres vivos, a disposição de cientistas em estudar e desenvolver novas tecnologias nessa área e o interesse do Estado em aplicar as descobertas alcançadas em soluções para os problemas sociais, econômicos, culturais e políticos.

Tendo em vista as diversas posições dos países no que se refere ao desenvolvimento científico e tecnológico, cabe a cada um estabelecer prioridades e estratégias próprias para aproveitar as oportunidades que a Cooperação Internacional apresenta. No próximo item apresentam-se algumas considerações essenciais para o tratamento da $\mathrm{Cl}$ na formulação de políticas públicas de desenvolvimento científico e tecnológico no Brasil.

I.2 Elementos essenciais para o tratamento da Cooperação Internacional como instrumento das Políticas Públicas de desenvolvimento em C\&T no Brasil

A Cooperação Internacional em C\&T no Brasil se apresenta como um importante componente da sua política externa,por se configurar como uma janela de oportunidades a um nível de conhecimento que o País levaria muito tempo para alcançar isoladamente. Essa idéia é compartilhada com a de Marcos Troyjo que afirma:

Para um país como o Brasil, a participação efetiva e a atenção premente à temática científico-tecnológica representam uma janela de oportunidade para a expansão de sua projeção internacional. Ao contrário de outros setores da relação entre os Estados, o espaço científico e tecnológico, e particularmente o desenho da Sociedade Global da Informação, marca-se por uma agenda internacional em construção, erigida, sobretudo por atividades de Cooperação Internacional. (TROYJO, 2003, p. 165, grifo do autor).
Em primeiro lugar, não se pode pensar uma política de cooperação internacional em C\&T que não seja de longo prazo, já que as atividades se concentram na fronteira da ciência, onde freqüentemente se desconhecem o ritmo de suas descobertas e os rumos do desenvolvimento, além das conseqüentes atividades de P\&D e externalidades que podem gerar novas tecnologias ou serem aproveitadas por diversos ramos da ciência.

A participação de equipes brasileiras em colaborações internacionais é elemento essencial para a formulação de uma política de cooperação em C\&T. Segundo estudos sobre a dinâmica social da ciência, a escolha estratégica dos cientistas segue as razões pelas quais se busca trabalhar em colaborações internacionais. Informações levantadas em vários artigos enumeraram os motivos que levam os cientistas a procurar colaborações de pesquisa (BOZEMAN e CORLEY, 2004, pp. 60 I-2):

\section{- Acesso a especialidades;}

- Buscar estruturas e recursos de pesquisa que não estão disponíveis para um grupo em seu país;

- Encorajar a fertilização cruzada entre disciplinas;

- Melhorar o acesso a recursos financeiros;

- Obter prestígio e visibilidade;

- Aprender conhecimento tácito sobre uma determinada técnica;

- Reunir conhecimento para resolver problemas grandes e complexos;

- Melhorar a produtividade;

- Formar recursos humanos;

- Incrementar a especialização da ciência;

- Diversão e prazer dos próprios cientistas.

O Brasil deve se aproveitar dessa gama de fatores sociais que motivam pesquisadores a buscar trabalhos em colaborações internacionais para fomentar a cooperação internacional em grandes empreendimentos científicos que proporcionem o desenvolvimento da C\&T no Brasil. Esta estratégia deve estar aliada ao incentivo da participação da iniciativa privada a procurar novos conhecimentos científicos e tecnológicos a serem aplicados nas próprias empresas, a fim de criar um ambiente favorável à inovação a partir das demandas da própria ciência (science push) ou do mercado (demand pull) ${ }^{4}$ dentro de um Sistema Nacional de Ciência e Inovação Tecnológica ${ }^{5}$.

No que tange à consolidação do conhecimento científico, devese atentar também para a criação de pólos de C\&T no País, por meio do estabelecimento de centros de pesquisa e ativi-

4 Science push ou "impulsão científica" é entendida como o processo de geração de inovações tecnológicas acionado pela adoção e difusão de novos conhecimentos científicos. Já demand pull, ou "atração de mercado", se baseia na hipótese central de que seja o mercado que determinaria a mudança tecnológica; Em outras palavras, é o funcionamento do sistema econômico que cria e fortalece a interação efetiva entre instituições de pesquisa e empresas comerciais" (CRIBB, 2002). Ambas são tidas como "ferramentas tradicionais de geração de inovações" (HAYNE, 2003, p. 34).

5 Já Sistema Nacional de Ciência e Inovação Tecnológica (SNCIT), “é uma rede de instituições nos setores público e privado cujas atividades e interações iniciam, geram, importam, modificam e difundem novas tecnologias”. (SÁENZ \& SOUZA-PAULA, 200I, p. 47). 
dades de colaboração científica em nível internacional, ações que permitem o desenvolvimento de novas tecnologias e estudos na fronteira do conhecimento, profundamente integrados às empresas. A pesquisa em ciência básica é, nesse sentido, tão fundamental quanto a pesquisa aplicada, e precisa ser encadeada num "sistema vital de conhecimentos" (SÁENZ \& SOUZAPAULA, 200 I, p. 48), de forma a garantir um arcabouço em ciência e tecnologia que atenda às demandas por insumos necessários para a promoção de inovações de acordo com as necessidades da realidade brasileira.

Ainda com relação à disseminação e consolidação do conhecimento adquirido em participações internacionais de cientistas brasileiros, outro ponto a ser previsto numa política de cooperação internacional em C\&T é tornar fundamental e definir estratégias para: a) selecionar áreas do conhecimento que tenham natureza ou aplicações multidisciplinares; b) formação de recursos humanos altamente especializados em centros no exterior; c) a permanência destes em instituições brasileiras por tempo suficiente para fixar as descobertas científicas na comunidade acadêmica nacional, seja em cursos de graduação ou pós-graduação; e d) promover a sua vinculação temporária ou permanente às empresas, locus da inovação tecnológica, de forma a transferir diretamente novas tecnologias ao setor produtivo.

Esses elementos essenciais precisam ser equacionados sob uma visão estratégica direcionada ao desenvolvimento científico e tecnológico, campo que tem se tornado cada vez mais determinante para o bem estar dos indivíduos e a condição econômica dos países. O item 2.3 apresenta uma visão da cooperação com esse propósito. Antes, se faz necessário discorrer sobre os principais atores da cooperação internacional e seus papéis no desenvolvimento científico e tecnológico.

\section{I.2.I Os Atores da Cooperação Internacional em Ciência e Tecnologia para o Desenvolvimento}

Os atores da Cooperação Internacional em C\&T são os cientistas, as instituições de pesquisa, as universidades, as empresas e outros agentes do setor privado, e o Estado, representado pelas instituições de formulação, gestão e agências financiadoras de políticas e programas de C\&T. Entretanto, foi identificado por este trabalho uma carência de estudos sobre o papel específico de cada um deles para o desenvolvimento científico nacional, fato que motiva estudos mais específicos que podem ser feitos futuramente.

Os cientistas são a mola motriz da Cooperação Internacional em C\&T. O seu sucesso será maior quanto melhor for o nível que os pesquisadores tiverem. Da mesma forma, o tipo de cooperação que um país fará será determinado pela perspectiva de desenvolvimento que assumida por sua comunidade científica. Os cientistas também são o principal veículo de comunicação e integração com comunidades científicas de outros países; a cooperação internacional em C\&T será tão ampla quanto $o$ acesso dos pesquisadores às instituições e grupos internacionais de pesquisa e desenvolvimento.

O País deve levar em consideração a organização e o grau de desenvolvimento que se encontra a comunidade científica nacional, analisando-as segundo as áreas estratégicas distintas, em função de suas diversas especificidades; recursos estruturais, financeiros e humanos necessários para desenvolvimento da medicina são substancialmente diferentes daqueles requeridos pelas engenharias, pela tecnologia da informação ou pelas ciências sociais de um modo geral. Portanto, os esforços de cooperação internacional devem estar relacionados às necessidades para o desenvolvimento científico que cada uma das áreas do saber exige para seguir sua evolução. É importante, também, concentrar esforços naqueles setores cujos avanços assumem externalidades em outras áreas científicas, tais como as ciências e tecnologias convergentes (nano e biociências, ciências cognitivas e ciência da informação). Setores como a medicina e as ciências agrárias assumiram papel de destaque para o desenvolvimento brasileiro ao longo da História (MONTOYAMA, 2000).

As universidades assumem um papel importante, pois agem tanto na formação de cientistas quanto na realização de pesquisas. Por se configurarem como autarquias, é comum observar universidades públicas e privadas realizando atividades de cooperação internacional sem qualquer apoio do governo, seja em nível municipal, estadual ou federal. Uma atividade comum das universidades é o estabelecimento de acordos de cooperação inter-universitária, geralmente abarcando intercâmbio de alunos, professores, projetos de pesquisa e financiamento conjunto de projetos específicos. Entretanto, o Estado ainda é o principal motivador para essas atividades, pois o desenvolvimento natural das atividades, iniciado pelo intercâmbio, requer aportes financeiros cada vez maiores, o que torna difícil a uma universidade arcar sozinha com os custos de atividades de pesquisa em nível internacional no médio e longo prazos.

As instituições de pesquisa, assim como as universidades são atores determinantes para o desenvolvimento científico que a Cooperação Internacional pode proporcionar. São esses atores que possibilitam a fixação do conhecimento adquirido pelos cientistas que foram ao exterior, e a sua estrutura é que permitirá o desenvolvimento de pesquisas visando a soluções para os problemas da sociedade. No Brasil existem universidades que concentram centros de excelência em pesquisa científica e tecnológica, como a Universidade Federal do Rio de Janeiro 
(UFRJ), que tem a antiga Coordenação dos Programas de PósGraduação em Engenharia (COPPE) ${ }^{6}$, e instituições independentes que realizam atividades de $P \& D$ e não são vinculadas a nenhuma universidade, como a Fundação Oswaldo Cruz (FIOCRUZ) e o Instituto Nacional de Pesquisas Espaciais (INPE). Entretanto, este último grupo de atores se diferencia no que se refere ao papel desempenhado na Cooperação Internacional, pois não contribuem diretamente na formação ou capacitação de recursos humanos em nível acadêmico (graduação, mestrado ou doutorado).

A iniciativa privada, seja sob a forma de empresas ou indústrias, assumem importância em estágios diversos do processo de desenvolvimento científico obtido a partir da cooperação internacional em C\&T.Assume importante papel no financiamento de novos empreendimentos científicos por ser o nicho onde ocorre a transformação das novas propostas tecnológicas em inovações de produto ou processo, a partir da absorção de parte da comunidade científica em suas dependências. Podem liderar a criação de pólos de estudos de aplicação das novas tecnologias obtidas a partir do acesso à pesquisa realizada nos centros mais avançados do mundo proporcionado pela cooperação internacional.

O Estado é o ator indispensável para viabilizar investimentos públicos e privados para a construção de estrutura de pesquisa necessária ao desenvolvimento em C\&T.Além do apoio financeiro, é ele quem tem o poder de promover a Cooperação Internacional em C\&T por meio de políticas públicas geridas por suas instituições. Assim, o Estado é o ator que torna possível o desenvolvimento científico e tecnológico proveniente das atividades de cooperação internacional. Seu papel perpassa todos os demais atores, pois é capaz de financiar grandes empreendimentos científicos internacionais de longo prazo ou incentivar a formação e capacitação de recursos humanos, e é o único ator que pode celebrar acordos de cooperação internacional com outros países, e da mesma forma defender e representar interesses nacionais em grandes foros mundiais como a Organização Mundial do Comércio (OMC), a ONU e o CERN.

Apresentados os atores e seus papéis na Cooperação Internacional em C\&T, explicita-se na Tabela I a competência de cada um no âmbito da cooperação internacional em ciência e tecnologia. Em seguida, será apresentada uma visão estratégica que a cooperação pode assumir no âmbito do desenvolvimento científico e tecnológico no Brasil.

\subsection{Estratégia de Cooperação Internacional voltada ao Desenvolvimento Científico e Tecnológico Brasileiro}

A importância estratégica da Cooperação Internacional em C\&T é ressaltada por Celso Amorim (1994), que defende a necessidade de avaliar as condições que o Brasil dispõe para obter vantagens significativas com países mais desenvolvidos. Propõe, também, que a cooperação internacional em C\&T deve estar intimamente ligada à política exterior brasileira, e não deve ser tratada como alternativa ao esforço interno de desenvolvimento, uma vez que só é possível cooperar nesse sentido se o País já dispuser de alguma estrutura científica e tecnológica própria. $\bigcirc$ autor afirma, ainda, que "a cooperação só será verdadeiramente frutífera quando houver complementaridade real de interesses" (p. 162). O grande desafio do Brasil e dos demais países em desenvolvimento, na opinião do atual Ministro das Relações Exteriores, é o de desenvolver uma capacidade de absorção e geração de tecnologia.

A $3^{\text {a }}$ Conferência Nacional de C\&T pautou a Cooperação Internacional como marco da política de C\&T brasileira, e apontou como diretriz estratégica "intensificar e explorar novas oportunidades de cooperação internacional em Ciência, Tecnologia e Inovação" (MCT, 2002, p. 70). Esse ramo da política nacional de C\&T implica:

- Intensificar esforços de reforma da Cooperação Inter-nacional;

- Melhorar a qualidade da cooperação, fortalecer sua dimensão institucional e ampliar a capacidade brasileira em redes internacionais de pesquisa;

- Diversificar o leque de parceiros internacionais do Brasil e promover a cooperação com países em desenvolvimento;

- Incentivar a participação de empresas brasileiras em alianças tecnológicas internacionais;

- Atrair empresas estrangeiras para realizar pesquisa no País.

Cabe justificar, também, a importância do Estado brasileiro em buscar a Cooperação Internacional para somar os seus esforços para desenvolvimento em C\&T, uma vez que, segundo o Livro Branco do Ministério da Ciência e Tecnologia,"a pesquisa e o desenvolvimento têm, hoje, caráter necessariamente internacional" (p. 30).Ao mesmo tempo, argumenta o Livro, os países desenvolvidos acabam por concentrar os avanços científicos e tecnológicos e, como conseqüência, acentuam cada vez mais a desigualdade dos níveis de desenvolvimento entre os países. Assim, somente um esforço coordenado a partir do Estado

6 Hoje chamada Instituto Alberto Luiz Coimbra de Pós-Graduação e Pesquisa de Engenharia. 
Tabela I

Os atores da cooperação internacional em C\&T

\begin{tabular}{|c|c|c|}
\hline Ator & Atuação & Papel estratégico para o desenvolvimento em C\&T \\
\hline \multirow[b]{2}{*}{ Cientistas } & $\begin{array}{l}\text { Geração e transferência de } \\
\text { conhecimento }\end{array}$ & Mola motriz do desenvolvimento científico e tecnológico \\
\hline & $\begin{array}{l}\text { Veículos de comunicação e } \\
\text { integração com comunidades } \\
\text { científicas internacionais }\end{array}$ & $\begin{array}{l}\text { Permite acesso ao conhecimento científico e atividades de } \\
\text { P\&D nos países mais avançados. }\end{array}$ \\
\hline \multirow{3}{*}{ Universidades } & $\begin{array}{l}\text { Formação e capacitação de } \\
\text { recursos humanos }\end{array}$ & $\begin{array}{c}\text { Provedor de mão de obra qualificada para atividades de P\&D } \\
\text { no setor privado e incubadora de estoques de pessoal para } \\
\text { atividades em C\&T }\end{array}$ \\
\hline & $\begin{array}{l}\text { Estrutura de pesquisa e } \\
\text { desenvolvimento }\end{array}$ & $\begin{array}{l}\text { Lugar-comum para a fixação do conhecimento adquirido pela } \\
\mathrm{Cl} \text { e a sua transformação em soluções para os problemas do } \\
\text { País. }\end{array}$ \\
\hline & Integração com o setor produtivo & $\begin{array}{l}\text { Proporcionar a transferência de tecnologia para o setor } \\
\text { privado de modo a garantir um estoque para inovações } \\
\text { tecnológicas }\end{array}$ \\
\hline \multirow{2}{*}{$\begin{array}{l}\text { Laboratórios e centros } \\
\text { de pesquisa }\end{array}$} & $\begin{array}{l}\text { Estrutura de pesquisa e } \\
\text { desenvolvimento }\end{array}$ & $\begin{array}{l}\text { Lugar-comum para a fixação do conhecimento adquirido pela } \\
\mathrm{Cl} \text { e a sua transformação em soluções para os problemas do } \\
\text { País. }\end{array}$ \\
\hline & Integração com o setor produtivo & $\begin{array}{l}\text { Proporcionar a transferência de tecnologia para o setor } \\
\text { privado de modo a garantir um estoque para inovações } \\
\text { tecnológicas }\end{array}$ \\
\hline \multirow{2}{*}{$\begin{array}{l}\text { Setor privado (empresas } \\
\text { e indústrias) }\end{array}$} & $\begin{array}{l}\text { Financiamento à pesquisa } \\
\text { científica e tecnológica }\end{array}$ & $\begin{array}{c}\text { Fornecer aporte financeiro necessário ao desenvolvimento } \\
\text { das atividades de P\&D promovidas pelos cientistas nas } \\
\text { universidades e centros de pesquisa }\end{array}$ \\
\hline & $\begin{array}{l}\text { Integração com a estrutura de } \\
\text { pesquisa e desenvolvimento em } \\
\text { C\&T nacional }\end{array}$ & $\begin{array}{c}\text { Transformar novos conhecimentos em inovações tecnológicas } \\
\text { a serem empregadas na solução de problemas nacionais }\end{array}$ \\
\hline \multirow{4}{*}{ Estado } & $\begin{array}{l}\text { Apoio institucional à cooperação } \\
\text { internacional }\end{array}$ & $\begin{array}{l}\text { Garantir suporte institucional para que cientistas assumam } \\
\text { responsabilidades em grandes empreendimentos científicos } \\
\text { internacionais e defender os seus interesses perante } \\
\text { organizações internacionais como OMC, ONU e CERN. }\end{array}$ \\
\hline & $\begin{array}{l}\text { Políticas públicas para formação } \\
\text { de recursos humanos }\end{array}$ & $\begin{array}{l}\text { Apoio financeiro e institucional para a formação e qualificação } \\
\text { de cientistas de acordo com as necessidades nacionais }\end{array}$ \\
\hline & $\begin{array}{l}\text { Políticas públicas de fomento à } \\
\text { pesquisa }\end{array}$ & $\begin{array}{c}\text { Apoio financeiro e institucional para a formação de pólos de } \\
\text { pesquisa em } \mathrm{C} \& \mathrm{~T} \text { capazes de fixar o conhecimento obtido } \\
\text { por meio da } \mathrm{Cl} \text { e transformá-lo em novas tecnologias } \\
\text { adequadas à realidade nacional }\end{array}$ \\
\hline & $\begin{array}{l}\text { Gestão da Cooperação } \\
\text { Internacional em C\&T }\end{array}$ & $\begin{array}{c}\text { Apoio institucional para o perfeito desenvolvimento das } \\
\text { atividades de } \mathrm{Cl} \text { desde a celebração dos Acordos } \\
\text { Internacionais até o acompanhamento e avaliação dos } \\
\text { resultados }\end{array}$ \\
\hline
\end{tabular}

Obs.: Organizado pelo autor

pode garantir o acesso ao conhecimento científico de fronteira "internacionalmente disponível” (idem), concentrado "num punhado de países avançados" (ibidem) e sua disseminação e adaptação às realidades nacionais, de modo a promover sucessivas adaptações da estrutura científica e tecnológica necessária para impulsionar o desenvolvimento brasileiro.

Para elucidar melhor a idéia apresentada, cabe apontar um exemplo fictício do professor Alberto Santoro (2000), físico da
UERJ e do CERN, que traça um caminho para o desenvolvimento científico brasileiro em Física de Altas Energias, a partir de uma iniciativa estatal de cooperação internacional, focando um grupo que trabalha em Física de Altas Energias.

Santoro argumenta que a estratégia se inicia com uma decisão do Governo Federal de "apoiar 3 centros, ou pólos nacionais de FAE” (p. I44), com algumas exigências que permitiriam ajudar o País a desenvolver a ciência nessa área. Os investimentos se- 
riam destinados, num primeiro momento, ao financiamento de visitas e de visitantes aos grandes centros de pesquisa no mundo, que trabalhariam em colaboração a partir de acordos internacionais de Cooperação em C\&T.

Os órgãos de pesquisa nacionais seriam incentivados pelo Estado a apoiar os cientistas a assumir responsabilidades em experimentos internacionais, podendo "discutir, projetar, executar, testar, implementar, monitorar e controlar uma parte de um grande detector (de partículas), desde que a Física fosse a mola mestra, a coluna vertebral do processo" (idem, p. I45). O próximo passo seria a decisão da comunidade científica internacional, então acrescida de cientistas brasileiros, de promover uma atualização na estrutura utilizada para pesquisa num laboratório científico internacional do qual façam parte. $\bigcirc$ Brasil ficaria responsável, nesse exemplo fictício, pela construção de um magneto supercondutor para possibilitar as medidas das partículas em estudo no grande detector. Seria firmado, então, um acordo de Cooperação Internacional entre o Brasil e os demais países que tomarem parte nesse empreendimento científico.

Alberto Santoro segue seu exemplo sugerindo que, a partir dessa decisão, se inicia uma reação em cadeia que permeia todos os setores da economia brasileira. O grupo de físicos responsável pela construção do magneto "juntar-se-ia com outras instituições, incluindo empresas, para realizar o projeto" (idem) no Brasil. Acionaria os setores siderúrgico e de indústria pesada para construir o magneto supercondutor, sempre com a participação de físicos e engenheiros de Altas Energias para transferir a tecnologia necessária.A partir da necessidade crescente de recursos humanos especializados, seria financiada a participação de especialistas, nacionais e estrangeiros, para a realização de seminários, mini-cursos e contatos com outros engenheiros e físicos que serão os futuros especialistas nessa tecnologia. O Físico amplia o escopo do seu exemplo ao propor que também seriam contatados os setores industriais de eletrônica, fibra ótica, de mecânica fina e de componentes em geral, necessários para a construção do aparato instrumental de pesquisa, para participação nos projetos.

Nesse momento, o número de atores envolvidos no projeto torna-o passível de exportar aplicações da tecnologia desenvolvida ao setor produtivo, fenômeno conhecido como Inovação Tecnológica. Santoro cita como principal resultado o desenvolvimento de um projeto para construção de um acelerador de partículas no Brasil que contemplasse "um setor para tratamento do câncer ${ }^{7}$, um setor de produção de feixe de partículas com fins industriais e microeletrônica, e um feixe para pequenos experimentos em física de partículas, fundamental para alimentar o desenvolvimento" (PP. I45-I46). Esse exemplo, mesmo que fictício, permite entendimento de como a FAE e a Cooperação Internacional em C\&T podem contribuir para a transferência de tecnologia de ponta para o Brasil, a partir do tímido apoio à visitação a importantes laboratórios internacionais, passando pela participação na construção de parte da sua estrutura, até a fixação de tecnologia no país e de inovações tecnológicas às indústrias nacionais a partir do conhecimento adquirido durante o processo.

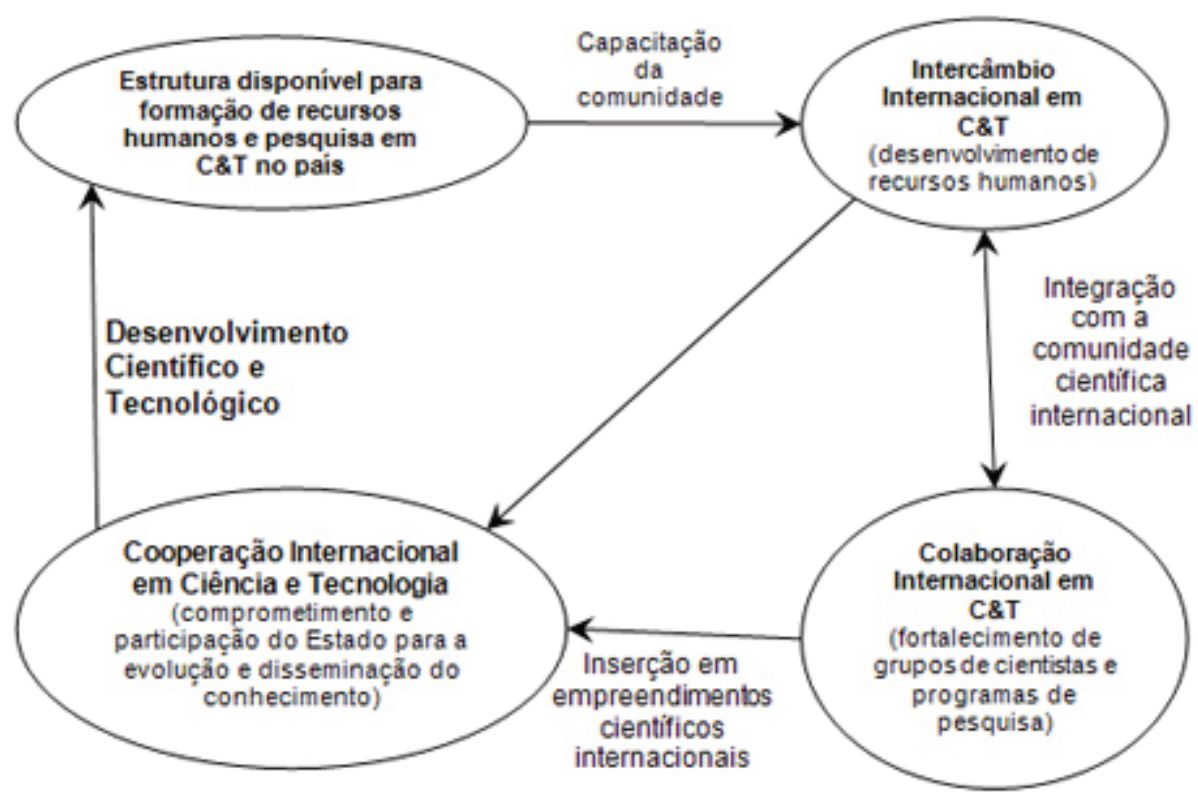

Figura I - Fluxograma da Cooperação Internacional para o desenvolvimento científico e tecnológico (adaptado pelo autor a partir do exemplo proposto pelo físico Alberto Santoro; 2000).

7 Já é conhecida, no meio científico, a contribuição da FAE para a medicina especializada no seu tratamento. 
O quadro a seguir foi elaborado a partir do exemplo do professor Santoro e das considerações apresentadas até aqui.

O fluxograma permite a visualização da estratégia da Cooperação Internacional voltada ao desenvolvimento em C\&T. Em primeiro lugar, como apontado por Celso Amorim (1994), toda e qualquer experiência de $\mathrm{Cl}$ se inicia, necessariamente, por uma capacidade já instalada no país, seja em estruturas de pesquisa, seja em recursos humanos. Somente com uma organização interna mínima é possível vislumbrar a absorção e adaptação às condições nacionais do conhecimento resultante dos empreendimentos científicos internacionais. É necessário, portanto, que uma estratégia de Cooperação Internacional voltada ao desenvolvimento em C\&T concentre investimentos institucionais naquelas áreas que já se encontram em condições de acompanhar o ritmo do avanço da ciência.

Ao contar com uma base capaz de formar cientistas com razoável nível, o intercâmbio internacional é uma alternativa para a formação de especialistas em áreas que o país ainda não tem condições de formar. Projetos que vislumbram a participação em eventos científicos ou a complementação da formação de recursos humanos a partir de pesquisas em níveis de pós-graduação, são iniciativas que abrem janelas de oportunidades para cientistas brasileiros. Nesse sentido, esta etapa é vital para a inserção da comunidade científica nacional naquelas atividades científicas internacionais que estão na fronteira do conhecimento.

As colaborações internacionais são admitidas neste trabalho como um ponto intermediário no processo. Elas significam o fortalecimento dos laços entre cientistas nacionais e estrangeiros em ações que tenham um significado concreto em termos de desenvolvimento científico. Estas iniciativas permitem a integração da comunidade científica brasileira naquelas atividades que estão na fronteira do conhecimento humano.

Cabe observar que as experiências de intercâmbio geram atividades de colaboração internacional, que por sua vez geram novos intercâmbios, num ciclo replicável tantas vezes quanto for possível, tal qual a perspectiva de expansão das redes de contatos entre os cientistas do mundo. Entretanto, conforme explicitado no item 2.I, essas iniciativas envolvem interesses individuais de cientistas, e pode-se afirmar que não contribuem necessariamente para o desenvolvimento científico e tecnológico de um país; pelo contrário, assumem a condição perversa de aprofundar as desigualdades regionais históricas da C\&T no País.

É nesse momento que a Cooperação Internacional ganha significado como instrumento de política pública para desenvolvi- mento científico e tecnológico. A partir de acordos estabelecidos entre os países, existe um comprometimento do Estado em garantir que a participação em empreendimentos científicos internacionais, que ampliam a fronteira do conhecimento humano e geram benefícios à sociedade, sejam transferidos e internalizados num contexto de transformação dos avanços da ciência em soluções para os problemas sociais nacionais.

Essas soluções são derivadas do desenvolvimento científico e tecnológico, que amplia os níveis de educação dos indivíduos, capacita a indústria para adaptar tecnologias e gerar inovações tecnológicas, ampliam a atividade econômica a geração de renda, e desenvolvem a estrutura disponível no país para novos empreendimentos de intercâmbio e colaborações científicas internacionais, consolidando um ciclo virtuoso dentro do desenvolvimento em C\&T nacional.

\section{Cooperação Brasil - CERN: Histórico e Perspectivas para o Desenvolvimento Científico Nacional}

\section{I Relato da Participação Brasileira no CERN}

A participação brasileira no CERN é percebida desde a sua fundação, sendo o físico Roberto Salmeron um dos 10 primeiros físicos experimentais contratados pelo Centro e tendo trabalhado por 25 anos até se aposentar (Salmeron, 2004, p. I).

Apesar disso, a colaboração da comunidade científica nacional com o CERN só se desenvolveu profundamente a partir de meados da década de 1980, quando esta começa a participar da construção de novos experimentos. Não há quase nenhum registro da participação brasileira além da formação de jovens cientistas até então.

Desde os anos de 1980 os cientistas brasileiros têm participado ativamente de diversos experimentos do CERN, desde a concepção dos equipamentos à execução de atividades de pesquisa e análise de resultados. $O$ grande destaque dessa participação brasileira se deu com o apoio financeiro do Governo Federal, por meio do $\mathrm{CNPq}$, à construção dos componentes que fariam parte do experimento ATLAS (A Toroidal LHC Apparatus), construído no LHC entre 1998 e 2007. Essa atividade possibilitou a transferência de tecnologia criada no CERN para a indústria brasileira com a interveniência dos cientistas brasileiros, responsáveis pela confecção de circuitos eletrônicos. Outro importante exemplo foi a cessão de patente tecnológica pelos EUA para que um chip criado por pesquisadores brasileiros, batizado de "CARIOCA" (CERNAnd RIO Current Amplifier), pudesse ser confeccionado no Brasil e instalado no CERN em meados da década de 1990 (DUARTE, 2004). 
A participação brasileira no CERN se justifica pela presença de uma comunidade científica da área de FAE proeminente no País. Segundo o Centro Brasileiro de Pesquisas Físicas (CBPF, 2007) há dois fatores que o colocam em posição favorável para participação em colaborações internacionais como o CERN: o número de físicos bem formados, em pé de igualdade com os representantes dos países mais avançados em C\&T, e a indústria nacional, que atingiu bom grau de desenvolvimento para apoiar a atividade da comunidade científica nacional, especialmente para contribuir na construção de novos equipamentos.

Em termos de desenvolvimento científico, entre 1990 e 200224 cientistas brasileiros fizeram viagens ao CERN, sendo que metade deste grupo fez visitas regulares (por mais de 3 anos consecutivos) em razão de sua participação nos experimentos do CERN. Segundo dados do CNPq (Anexo 5), há registros de 43 viagens entre 1998 e 2002, período em que se alocaram aproximadamente $R \$ 345.566,95$ em diárias e passagens aéreas (em paridade cambial atual). Traçando uma média, tem-se aproximadamente 8 pesquisadores/ano a um custo de R $\$ 69$. II 3,39 anuais.A partir de 2003 houve uma mudança na gestão dos pedidos de viagem ao CERN, passando de demanda espontânea (feita sempre que houvesse necessidade de viajar) a uma demanda atendida via edital, processo usado na quase totalidade dos programas de cooperação internacional do Conselho.

Entretanto, o sistema de editais para apoio às visitas científicas ao CERN não se mostrou eficaz para atender à demanda da comunidade científica nacional. Primeiro, porque não era possível planejar visitas ao CERN com exatidão dentro do período de dois anos (a programação de atividades é feita com tempo de antecipação inferior a um ano). Em segundo lugar, a participação brasileira alcançava um novo status, assumindo responsabilidades na construção e operação dos novos experimentos no novo acelerador de partículas da Organização, o LHC. Isso requeria, além do apoio financeiro às visitas, o pagamento de anuidades para operação daqueles experimentos em que os cientistas brasileiros iriam participar. Após negociações entre o CERN, CNPq e a comunidade científica nacional, ficou acertado que o Conselho passaria a pagar apenas as anuidades, cabendo aos pesquisadores do País procurar apoio para suas viagens. Ao todo, desde 2004, foram aplicados R\$737.316,73 com as anuidades dos experimentos ATLAS, LHCb (Large Hadron Collider beauty), CMS (Compact Muon Solenoid) e ALPHA (Antihydrogen Laser Physics Apparatus), recursos que têm garantido a manutenção do acesso das equipes brasileiras às descobertas, informações e tecnologias desses detectores. Para se ter uma idéia do que isso representa, o orçamento anual do CERN beira a casa de um bilhão de dólares. $O$ País contribui, portanto, com uma parcela mínima dos custos totais do LHC e tem o mesmo acesso8 que grandes potências econômicas e científicas, como EUA, Japão e Alemanha, que gastam até 100 vezes mais, segundo informações do CNPq.

Percebe-se, contudo, que o apoio não é completo. É necessário não só garantir o pagamento das anuidades, que reúnem uma soma considerável, mas também uma garantia mínima de custeio de visitas ao CERN, para aproveitar ao máximo as perspectivas de desenvolvimento oferecidas pela Cooperação Brasil-CERN: tanto a transferência de tecnologia sem ônus, quanto a integração da comunidade científica nacional com os grupos científicos de mais de 80 países que participam das atividades naquele centro.

O item a seguir elucida o contexto e os principais motivos que levaram à assinatura do Acordo Brasil-CERN e relata o que ocorreu no período entre o término de sua vigência em 2000 até a assinatura de um novo acordo em 2006.

\section{I.I O Acordo de Cooperação Brasil-CERN}

O encerramento do conflito ideológico conhecido como Guerra Fria resultou no incremento da velocidade e do intercâmbio internacional da informação, que colocam pesquisadores e centros de pesquisa de diferentes países em contato direto, de forma a tornar o acesso à comunidade científica internacional muito mais dinâmico e aberto, em contraposição à situação vigente até a década de 1980. A mobilidade internacional de pesquisadores de talento também se tornou mais simples. Mas ao mesmo tempo, a participação efetiva na comunidade internacional dependeu, desde então, de uma qualificação adequada, na medida em que requer a utilização de instrumentos científicos padronizados, linguagem e padrões de comunicação adequados, que, em sua ausência, podem gerar novas desigualdades e formas de concentração de recursos e qualificações.

Na medida em que a relevância econômica do conhecimento científico e tecnológico cresceu, intensificou-se a tendência de limitar sua difusão na legislação sobre propriedade intelectual e de barreiras governamentais à difusão de tecnologias consideradas sensíveis ou estratégicas. Esta tendência, entretanto, foi compensada pela intensa competição internacional de empresas e governos para vender suas tecnologias, e pela inexistência de fronteiras bem definidas entre conhecimento acadêmico, ou livre e o conhecimento privado, ou protegido (Schwartzman, 1993).

8 O CERN não faz qualquer tipo de restrição ao acesso de conhecimento ou tecnologia aos cientistas e pesquisadores que participam dos seus experimentos, quaisquer que sejam seus países de origem, desde que exista algum instrumento que estabeleça uma relação de cooperação internacional com a Organização.. 
O resultado é que o acervo básico da tecnologia moderna está disponível para os países que possuem suficiente massa crítica em ciência e tecnologia. Isso não se aplica a algumas poucas tecnologias militares e outras declaradas sensíveis, que ainda podem ter seu acesso controlado pelas grandes potências.

Face a natureza da ciência, que desconhece fronteiras, credos e raças, a integração entre comunidades científicas nacionais que apresenta um histórico de franco crescimento desde a revolução científica nos séculos XIV e XV.Atualmente, os veículos de informação têm tornado a comunicação entre atores de todo o mundo cada vez mais ampla, e o contato e o intercâmbio entre cientistas de diferentes nacionalidades vêm crescendo a taxas cada vez maiores?

Foram esses os principais fatores que proporcionaram a assinatura, em 1990, do Acordo de Cooperação Brasil - CERN. Este instrumento coroou a crescente e significativa participação brasileira nas atividades desse Centro, e a ampliação do alcance dos parceiros do laboratório europeu, após o fim da Guerra Fria, principalmente após a extinção dos entraves ao estreitamento das relações entre os países europeus e destes com o resto do mundo, quase que paralelamente ao rápido desenvolvimento do processo de integração da atual União Européia a partir da década de 1980. Esse acordo também foi possível ao Brasil em função de aqui haver uma comunidade científica em nível suficiente para acompanhar a pesquisa que se desenvolvia à época no CERN.

No acordo firmado (CNPq, 1990), Brasil e CERN manifestaram a concordância de que a pesquisa nas áreas de Física de Partículas, Engenharia e Ciência da Informação, principalmente, eram importantes para o desenvolvimento da ciência e para o progresso tecnológico. Essa idéia se refletiu no interesse Brasileiro de promover o crescimento sólido da comunidade científica nacional e o interesse em garantir oportunidades no longo prazo para os cientistas brasileiros. O CERN, por sua vez, visou se beneficiar do conhecimento da massa científica brasileira para somar esforços aos dos cientistas que já participavam das suas atividades de pesquisa e desenvolvimento (P\&D).

O Acordo Brasil-CERN, entretanto, teve sua vigência expirada em dezembro de 2000, e na época foram feitos contatos entre as duas Partes para a sua renovação. Em julho de 2002 o então Ministro da Ciência e Tecnologia do Brasil, Ronaldo Motta Sardenberg realizou uma visita ao CERN, tendo em vista o ex- celente desenvolvimento da atividade brasileira nesse Centro. $\mathrm{Na}$ oportunidade, o lado europeu fez uma oferta para que o Brasil passasse ao status de Membro Observador do Conselho Geral do CERN, com direito a voz nas suas discussões ${ }^{10}$, entrando para um seleto grupo de países formado pelos Estados Membros (com direito a voto) além de Japão, Estados Unidos, Federação Russa, Israel, Turquia e a UNESCO. Para tanto, o Diretor Geral do laboratório, professor Luciano Maiani e o Ministro brasileiro assinaram uma declaração conjunta (Joint Statement) que previa a formação de um grupo de estudos em conjunto para viabilizar o fortalecimento das relações BrasilCERN e preparar um novo Acordo de Cooperação Internacional que atendesse aos interesses de ambas as Partes.

Entre 2000 e 2006, não se chegou a nenhuma conclusão, e a Cooperação Brasil-CERN se deu apenas com o respaldo diplomático desse Joint Statement para ser operado. Em setembro de 2006 um novo acordo foi firmado nos mesmos moldes do seu antecessor, contemplando cooperação sob a forma de:

a) Visitas de cientistas brasileiros ao CERN;

b) visitas de representantes do CERN às instituições de pesquisa brasileiras;

c) intercâmbio de informação científica, inclusive publicações, revistas e periódicos;

d) intercâmbio de material científico e equipamentos necessários à realização de programas ou projetos de interesse comum;

e) outras formas de cooperação científica e tecnológica acordadas entre as Partes. (CNPq, 2006, cláusula II)

O Convênio prevê que todas as atividades derivadas serão objeto de acordos específicos que serão elaborados tempestivamente. No corrente ano (2008), estão em processo de negociação dois instrumentos, um voltado à participação e treinamento de estudantes no CERN e outro destinado à participação de instituições científicas e universidades brasileiras nos experimentos de FAE do CERN. Um ano após a assinatura do novo acordo, já há um esforço do governo brasileiro em estabelecer bases sólidas para a cooperação internacional com o CERN, contemplando tanto os cientistas quanto as instituições às quais eles pertencem.

9 É fato conhecido que o intercâmbio entre cientistas de diferentes países se dá no médio ou longo prazo, criando laços sólidos que se estendem às comunidades científicas dos diferentes países. (SALLES FILHO, 2000)

I0 Atualmente o Brasil é um Membro Colaborador 
Tal iniciativa se mostra alinhada à inspiração do CERN em contribuir para os avanços em C\&T dos países vinculados às suas atividades e à premissa da Cooperação Internacional para o Desenvolvimento Científico defendida neste trabalho, no qual é necessária a complementaridade de interesses dos atores e a garantia de transferir os avanços para o território nacional visando ampliar a capacidade de solucionar problemas nacionais. Trata-se de um importante avanço do apoio institucional do governo brasileiro em relação ao período 1990-2000, em que apenas foi celebrado, em adição ao Acordo Geral, um memorando de entendimentos para a participação de uma equipe brasileira na construção do experimento ATLAS, que será abordado no item 4.2, mesmo havendo mais duas propostas semelhantes submetidas pelos cientistas brasileiros.

Os itens seguintes se concentrarão em apresentar o desenvolvimento da atividade brasileira em três experimentos do CERN: ATLAS (A Toroidal LHC Apparatus), LHCb (Large Hadron Collider beauty) e CMS (Compact Muon Solenoid). Esses experimentos são detectores de partículas construídos em pontos específicos do grande acelerador LHC e estudam diferentes elementos que compõem a estrutura atômica. Os três foram escolhidos por contar com uma participação brasileira consolidada ao longo dos anos 1990, estar em pleno funcionamento e já apresentarem desenvolvimentos em P\&D.

\section{2 - O Experimento Atlas e suas Conseqüências para a Pesquisa Científica no Brasil}

O experimento chamado A Toroidal LHC Apparatus, ou ATLAS foi o único a contar com uma participação oficial brasileira por meio da assinatura de um Memorando de Entendimentos (MOU) em 1998. Foi projetado para explorar ao máximo o potencial oferecido pelo principal detector de partículas do CERN, o Large Hadron Collider (LHC), que começou a funcionar em meados de 2007 e ficará em operação por pelo menos 10 anos.A principal função do ATLAS será a busca por "novos e inesperados processos físicos” (ALMEIDA JÚNIOR, 2004, p. 6).

A Universidade Federal do Rio de Janeiro (UFRJ) possui cientistas que participam desse experimento desde 1988, antes mesmo da assinatura do Acordo Brasil-CERN. Essa participação foi fundamental para a consolidação da equipe brasileira nesse experimento e no CERN como um todo. A atividade da equipe chefiada pelo físico Fernando Marroquim Leão de Almeida Júnior teve início com a participação na construção, pesquisa e desenvolvimento de protótipos de equipamentos a serem utilizados nos aceleradores do CERN desde aquele ano.
Desde então, a equipe brasileira tem desenvolvido trabalhos em quatro frentes no ATLAS: desenvolvimento de equipamentos de informática (hardwares e softwares), análise de dados de protótipos, simulações para testar a viabilidade da estrutura criada e estudo sobre novas partículas a serem descobertas.

Apesar de ter sua participação oficial no ATLAS confirmada pelo CERN em 1994, o Brasil só se comprometeu financeiramente para a construção do detector em 1999, quando foi assinado o MOU. Esse memorando, assinado sob as diretrizes criadas no Acordo Brasil-CERN (mas sem qualquer relação de dependência para sua validade), previu que o Brasil financiasse a construção de equipamentos necessários à operação do detector. Esse custeio foi feito em seis parcelas anuais, até 2005, de cem mil francos suíços (algo em torno de 160 mil reais, na média de conversão de moeda), que foram gastos na compra e importação de componentes para construção, no Brasil, de 2.500 placas somadoras de circuitos eletrônicos impressos que foram instalados no ATLAS (ALMEIDA JÚNIOR, 2004). É importante informar que a confecção e testes desses circuitos foram feitos exclusivamente no País, pela UFRJ e pela indústria nacional.

A colaboração ATLAS permitiu à equipe brasileira confeccionar no País 2.500 placas somadoras de circuitos integrados. Essas placas serão responsáveis pela filtragem dos sinais provenientes do detector de partículas, passando para o banco de dados do ATLAS apenas os fenômenos físicos desconhecidos, que serão estudados cuidadosamente (ALMEIDA JÚNIOR, 1998-2004). Essa atividade ocorreu da seguinte forma: o CERN adquiriu os componentes para essas placas com recursos repassados pelo governo brasileiro a partir do MOU e os exportou para o Brasil. A equipe do professor Marroquim entrou em contato com a indústria brasileira, que reuniu esses componentes em placas de circuito integrado, que foram inteiramente testadas em seus níveis de resistência a radiação, calor e parâmetros no Brasil, na COPPE/UFRJ"'. Depois de testados e aprovados, esses circuitos somadores retornaram ao CERN para serem instalados no detector ATLAS. É importante observar que o programa (software) usado para operar esses circuitos também está sendo desenvolvido pela equipe brasileira.

Além dessa importante interação universidade-empresa, a participação no experimento ATLAS já rendeu outros exemplos de transferência de tecnologia para o Brasil, com chances de se reverterem em inovações tecnológicas e patentes. São elas (ALMEIDA JÚNIOR, 2004):

I I Segundo relatório do professor Marroquim, a atividade de testes dessas placas foi coordenada por um aluno de mestrado da UFRJ. 
a) Processamento de sinais de sonar passivo, em colaboração com a Marinha do Brasil (classificação de classes de navios);

b) Sistemas de apoio ao diagnóstico médico, em colaboração com o hospital universitário da UFRJ, para o combate a doenças como hepatite e tuberculose pulmonar;

c) Sistema de processamento para o sistema de energia elétrica, em colaboração com a Eletrobrás;

d) Processamento de voz, com possibilidade de apoio aos portadores de necessidade especiais, em colaboração com a Faculdade de Engenharia da Universidade de Porto (Portugal);

e) Identificação automática de placas de veículos automotores e de passeio, em colaboração com o CBPF;

f) Análise de qualidade de dados para áreas financeira e social (processamento de sinais para tratamento de dados faltantes ou incorretos [sic]);

g) Aplicação de modelos Web e instrumentação virtual para educação à distância em engenharia (laboratórios virtuais);

h) Instrumentação eletrônica para uso de sensores e processamento para detecção de sinais, em colaboração com a empresa Nokia.

Para constatar os impactos diretos na comunidade científica brasileira, é oportuno mostrar que, até 1998, a equipe do professor Fernando Marroquim contava apenas com quatro cientistas, que foram direta ou indiretamente responsáveis por 99 citações em congressos, conferências e notas internas e outras 55 publicações em diversos veículos de informação da comunidade científica nacional e internacional (ALMEIDA JÚNIOR, 2004). Além de citações e publicações, esses quatro cientistas já haviam concluído a orientação de sete teses de doutorado, duas de mestrado, doze trabalhos finais de graduação e setenta e sete projetos de iniciação científica entre 1994 e 1998. Esse expressivo número de trabalhos explicita perfeitamente a capacidade de disseminação do conhecimento adquirido junto ao CERN para a comunidade científica brasileira.

eis anos depois, o crescimento e desenvolvimento da equipe brasileira chegaram a um patamar expressivo. Informações fornecidas pelo professor Marroquim (2004) evidenciam que a equipe internacional que trabalha no ATLAS é da ordem de I.700 colaboradores de 144 universidades e centros de pesquisa do mundo, e que a equipe do Brasil conta com 40 colaboradores de 5 centros de pesquisa nacionais ${ }^{12}$, além de colaboradores de 6 centros de pesquisa nacionais entre doutores, mestres, graduados, alunos de doutorado, mestrado, graduação e até mesmo de ensino médio (Iniciação Científica Júnior e escolas técnicas) do Colégio Aplicação da UFRJ.A Física de Altas Energias não é a única área do conhecimento abordada pela equipe brasileira; Engenharia de Softwares e Eletrônica já têm significativa participação nas atividades do ATLAS. O número de publicações também aumentou substancialmente: foram concluídos, entre 1998 e 2005, 15 teses de doutorado, 9 dissertações de mestrado, 19 trabalhos de conclusão de cursos de graduação e 24 trabalhos de inicialização científica. Cabe ressaltar que esse desenvolvimento só foi possível a partir do compromisso assumido pelo Brasil em financiar a equipe brasileira no médio prazo.

Todos esses avanços são derivados da experiência da equipe brasileira adquirida nas atividades de construção e testes do detector ATLAS, que iniciou suas operações em 2007. Entretanto, segundo o professor Marroquim ${ }^{13}$, o Governo ainda não assinou um compromisso de longo prazo para garantir a participação brasileira no experimento depois de encerrada a sua etapa construção, pagando apenas as anuidades (membership fee), que entre 2002 e 2007 somaram $R \$ 272.038,07$. Essa demora implica em uma dificuldade de maior comprometimento da equipe brasileira nos trabalhos que serão desenvolvidos nos próximos anos. É importante que o Governo defina uma estratégia de apoio às atividades dos pesquisadores brasileiros no CERN para garantir o acesso aos conhecimentos e tecnologias que resultarão das atividades no ATLAS nos próximos 10 anos.

\section{3 - O Experimento LHCB e suas Conseqüências para a Pesquisa Científica no Brasil}

O Large Hadron Collider Beauty ( $\mathrm{LCHb}$ ) é mais um experimento que está sendo construído no acelerador LHC, e tem por objetivo principal o estudo da assimetria entre matéria e anti-matéria, além da física do quark $b$, a mais recente partícula subatômica descoberta nos anos 90 .

A equipe brasileira que participa desse experimento já tem algum tempo de contribuição, observada desde a primeira

12 Centro Brasileiro de Pesquisas Físicas (CBPF), Instituto de Estudos Avançados do Centro Tecnológico da Aeronáutica (IEAv/CTA-SP), Universidade Federal de São João Del Rei (UFSJ/MG), Instituto de Radiação e Dosimetria (IRD/RJ), Universidade Federal de Juiz de Fora (UFJM/MG) (ALMEIDA JÚNIOR, 2004).

13 Informações recebidas em conversa por e-mail no dia 6 de novembro de 2007. 
metade da década de 1990, com os professores Bernard Marechal e Leandro Salazar de Paula, da UFRJ.A participação desse grupo tem grande relevância para o desenvolvimento do experimento, e abrange os campos do desenvolvimento de detectores, ferramentas de análise de dados (softwares), e chips eletrônicos (hardware).

Um desses chips desenvolvidos foi o Cern And RIO Current Amplifier (CARIOCA), utilizando tecnologia de $25 \mu \mathrm{m} .{ }^{1415} \mathrm{Os}$ resultados dos testes desse chip realizados no CERN comprovaram sua eficácia para compor todos os experimentos do LHC (CMS, ATLAS, LHCb, entre outros). Esse trabalho permitiu ao Brasil obter a autorização para trabalhar com essa tecnologia, cuja patente é de uma indústria dos EUA, que não a cediam ao País por considerá-la sensível, segundo sua legislação. O Brasil obteve autorização para utilizar essa tecnologia na indústria nacional por ser responsável pela criação e desenvolvimento do chip CARIOCA no âmbito da colaboração LHCb (CERN Courier, 2000).

A participação brasileira nesse experimento, contudo, foi estruturalmente limitada, uma vez que a não renovação do Acordo de Cooperação Brasil-CERN, imediatamente após o seu término, e a ausência de um Memorando de Entendimentos que balizasse a participação brasileira, restringiram a atividade do grupo da UFRJ além do acompanhamento do que tem sido desenvolvido no LHCb.Além disso, houve problemas de financiamento, como salientado pelo professor Leandro de Paula, professor da UFRJ membro da equipe brasileira:

Não foi possível dar continuidade ao projeto que nos possibilitaria produzir detectores no Brasil, nem ampliar o projeto do CARIOCA por falta de financiamento. No momento não temos condições nem de participar de reuniões regulares da colaboração. Dessa maneira países como México, China e até Cuba estão obtendo maior atenção do CERN do que o Brasil. (DUARTE, 2004, p. 32)

Entre 2004 e 2006, entretanto, o LHCb também contou com apoio financeiro do CNPq para custeio das anuidades, tal como o ATLAS. Foram gastos R\$309.922,68 que garantiram a participação da equipe brasileira nas atividades de P\&D em FAE, mas também permanecesse necessária uma conclusão do Governo Federal sobre o apoio financeiro às visitas dos cientistas brasileiros ao CERN.

\section{4 - O Experimento CMS e suas Conseqüências para a Pesquisa Científica no Brasil}

A Colaboração CMS (Compact Muon Solenoid) foi criada para viabilizar a construção e operação de um detector, com o mesmo nome, no LHC, o grande colisor de partículas do CERN. Ele é um detector de amplo espectro, do ponto de vista da Física, projetado para estudar a origem das massas na física de partículas, por meio do registro de dados de alta luminosidade. Suas atividades em pesquisa científica iniciaram em meados de 2007 , quando se encerrou o cronograma proposto para sua construção. Seu projeto visa estudar num período de pelo menos 10 anos, eventos que estão além da fronteira do conhecimento conhecida atualmente, estudando inclusive as propriedades dos elementos componentes da luz (SANTORO, 2002).

A equipe brasileira, coordenada pelo professor Alberto Franco de Sá Santoro, da Universidade do Estado do Rio de Janeiro (UERJ), é composta por 30 pesquisadores de 7 universidades e centros de pesquisa brasileiros, a saber: UERJ, CBPF, UFRJ (USP), UNESP, UFBA e UFRGS ${ }^{16}$. Por se tratar de um experimento que acaba de ser iniciado, ainda não há registros de desenvolvimento de recursos humanos da mesma forma que pôde ser observado no ATLAS.

A equipe brasileira se propôs, junto ao CERN e ao CMS, a construir uma das 4 tampas de um ímã supercondutor, que somadas envolvem 10.000 toneladas de ferro. Essas tampas têm a função de fechar o campo magnético gerado pelo experimento. $O$ grupo brasileiro se comprometeu a essa atividade visando propiciar à indústria brasileira o envolvimento em projetos científicos de grande porte, a fim de mostrar a competência desse setor e abrir novos mercados (SANTORO, 2002).Vale ressaltar que essa atividade não é a única proposta que interessa à equipe brasileira, visto que existem outras no que se refere à instrumentação eletrônica e informática.

Além da colaboração para construção do experimento, o projeto do professor Santoro prevê a parceria para se construir nas universidades e centros de pesquisa nacionais envolvidos, uma rede integrada de computadores para transmissão de dados (GRID), que otimizaria o estudo das informações sem a necessidade de mobilização dos cientistas.

Esse projeto, contudo, passou por estudos por parte do Governo Federal e suas instâncias (MCT, CNPq, entre outros)

I4 I $\mu \mathrm{m}$ corresponde à milionésima parte do metro.

I5 Esse chip pode trabalhar em ambiente de alta taxa de radiação e produz resultados rápidos, da ordem de nanossegundos. 16 USP - Universidade de São Paulo, UNESP - Universidade do Estado de São Paulo, UFBA - Universidade Federal da Bahia e UFRGS Universidade Federal do Rio Grande do Sul. 
para que seja definida uma estratégia de apoio e financiamento à equipe do professor Santoro, sem que, ainda (2008) se tenha chegado a uma conclusão. A equipe conseguiu apoio da Financiadora de Estudos e Projetos (FINEP) para implementar a pesquisa com a GRID, que está sendo realizada na UERJ ${ }^{17}$. $O$ atraso para se chegar a um acordo com a comunidade científica pode acarretar num fraco aproveitamento das oportunidades de transferência de conhecimento e tecnologia pela equipe brasileira envolvida na colaboração CMS, tal como se observou no experimento LHCb. Desde 2004, o CNPq deixou a custear as viagens dos pesquisadores brasileiros e passou a pagar apenas as anuidades que garantem o acesso dos cientistas nacionais às atividades do LHC, que até 2007 somaram $\mathrm{R} \$ 102.742,38$ (cento e dois mil, setecentos e quarenta e dois reais e trinta e oito centavos), mas, tal qual os outros experimentos apresentados neste trabalho, carecem de um apoio substancial para garantir um número mínimo de visitas ao CERN e um comprometimento maior com as atividades que serão realizadas nos próximos anos, o que limitará as perspectivas de desenvolvimento científico e tecnológico provenientes dessa atividade, caso não seja revista a política de cooperação internacional com o CERN.

Para fins de uma compreensão mais dinâmica dos resultados alcançados pela equipe brasileira nos três experimentos ora relatados, elaborou-se um resumo dos pontos mais importantes no que se refere ao desenvolvimento em C\&T.

\section{Tabela II}

Resumo das atividades e resultados da participação brasileira nos experimentos do CERN

\begin{tabular}{|c|c|c|}
\hline EXPERIMENTO & ATIVIDADES & RESULTADOS \\
\hline \multirow[b]{3}{*}{ ATLAS } & Participação nas atividades de P\&D & $\begin{array}{c}\text { Mais de } 200 \text { citações em congressos e mais de } \\
60 \text { artigos publicados }\end{array}$ \\
\hline & Formação de Recursos Humanos & $\begin{array}{l}\text { Mais de } 40 \text { pesquisadores envolvidos, entre } \\
\text { doutores, mestres, graduados e alunos do } \\
\text { ensino médio. }\end{array}$ \\
\hline & Inovação tecnológica & $\begin{array}{l}\text { Montagem e teste de } 2.500 \text { placas de circuitos } \\
\text { eletrônicos integrados no Brasil em atividade } \\
\text { conjunta Universidade-Empresa. } \\
\text { Oferta feita pelo CERN para confecção, no } \\
\text { Brasil, de } 30 \mathrm{~km} \text { de cabos para transmissão de } \\
\text { dados a ser instalado no Detector. }\end{array}$ \\
\hline \multirow{3}{*}{ LHCb } & Participação nas atividades de P\&D & $\begin{array}{l}\text { Desenvolvimento de instrumentos de análise, } \\
\text { chips e detectores. }\end{array}$ \\
\hline & Formação de Recursos Humanos & $\begin{array}{l}\text { Formação de físicos, engenheiros e técnicos } \\
\text { envolvidos no experimento. }\end{array}$ \\
\hline & Inovação tecnológica & $\begin{array}{l}\text { Chip CARIOCA, elaborado com acesso a } \\
\text { propriedade intelectual cedida pelos EUA para } \\
\text { confecção pela indústria brasileira. }\end{array}$ \\
\hline \multirow{3}{*}{ CMS } & Participação nas atividades de P\&D & $\begin{array}{c}\text { Pretende-se detectar o Bóson de Higgs } \\
\text { (inédito) e estudar novos fenômenos físicos } \\
\text { em outras partículas. }\end{array}$ \\
\hline & Formação de Recursos Humanos & $\begin{array}{c}\text { Alunos de doutorado, mestrado e graduação jáa } \\
\text { iniciaram pesquisas sobre o CMS. }\end{array}$ \\
\hline & Inovação tecnológica & $\begin{array}{l}\text { GRID - rede de altíssima velocidade em } \\
\text { computação e supercomputação de dados já } \\
\text { instalada na UER], com recursos da FINEP. }\end{array}$ \\
\hline
\end{tabular}

Obs.: Elaborado pelo autor

17 O autor tomou conhecimento dessa atividade ao visitar o professor Santoro na UERJ em dezembro de 2006. 


\section{Conclusöes}

A ciência e a tecnologia têm se tornado condicionantes para o sucesso do processo de desenvolvimento dos países. Estados como EUA, Japão, Alemanha, França e Grã-Bretanha possuem centros de excelência em pesquisa científica e tecnológica os mais avançados do mundo, além de uma capacidade de formar recursos humanos de alto nível. Países como o Brasil, Rússia, China e Índia assumem um posto intermediário de desenvolvimento econômico e social, e não por acaso estão em um patamar similar parecido em termos científicos e tecnológicos.

Da mesma forma, sobre a distância entre países desenvolvidos, em desenvolvimento e pobres persiste a defasagem tecnológica entre eles, que é de tal forma que a simples transferência de tecnologia não resolve os problemas estruturais gerados dessa divisão, sendo necessário criar uma capacidade interna para absorver e transformar conhecimento em soluções para os problemas nacionais. Nesse sentido, a Cooperação Internacional torna-se uma alternativa altamente viável para encurtar essa distância, seja para a formação de recursos humanos no exterior, para a ajuda internacional na construção de centros de pesquisa ou na geração e transferência de conhecimento e tecnologias. Nesse cenário, a Cooperação Internacional pode contribuir para o desenvolvimento científico e tecnológico de países como o Brasil nos setores que se encontram em significativo atraso em relação às grandes potências científicas mundiais.

Assim, a estratégia da cooperação internacional voltada ao desenvolvimento científico brasileiro deve ser pensada de uma maneira mais dinâmica. Em primeiro lugar, é preciso desvincular as idéias de intercâmbio e colaboração internacional do conceito de cooperação internacional em C\&T. O primeiro significa a simples formação ou qualificação de recursos humanos e existe sem a necessidade de participação do Governo.A colaboração científica internacional se limita a grupos de cientistas e instituições em C\&T em projetos ou programas determinados. As externalidades do desenvolvimento científico de ambas as experiências não são facilmente percebidas ou absorvidas por outras áreas do conhecimento.

Para gerar desenvolvimento científico e tecnológico, a Cooperação Internacional deve se focalizar em áreas do conhecimento que já tenham um estágio avançado de formação de recursos humanos e integração com a comunidade científica internacional para ser realmente frutífera. Deve ser estabelecido um ciclo virtuoso que se inicia no estoque de conhecimento, estrutura e cientistas que são a base para experiências de intercâmbio e colaborações científicas internacionais, ambos funcionando como catalisadores da $\mathrm{Cl}$. $\mathrm{O}$ papel do Estado é fundamental para garantir o acesso à propriedade intelectual e apoio financeiro direto, por meio de agências de fomento à pesquisa, ou indireto, por meio de iniciativas de integração universidade-empresa e incentivos fiscais para investimentos do setor privado em atividades de C\&T. Iniciativas estatais também são ações imprescindíveis para criar uma estrutura de pesquisa necessária para criar e transferir conhecimento científico e tecnológico com vistas à geração de soluções para os problemas da sociedade brasileira.

Portanto, as políticas públicas de C\&T brasileiras devem compreender a Cooperação Internacional como um processo vital para o desenvolvimento da estrutura necessária ao País que vai promover soluções ao seu processo de desenvolvimento no século XXI.É ela quem permite ao País absorver conhecimento e capacitar de recursos humanos capazes de trabalhar na fronteira da ciência e assim acompanhar o ritmo de crescimento dos países mais avançados. Dada a importância estratégica da C\&T nos tempos atuais, a $\mathrm{Cl}$ pode ser uma componente igualmente importante para reduzir a distância entre o Brasil e os países centrais.

A Cooperação Brasil-CERN gerou desenvolvimento em C\&T para o País ao longo de 18 anos, mas ele foi limitado proporcionalmente ao apoio do Estado. A formação e o desenvolvimento de recursos humanos foi bastante expressiva, já que depois de catorze anos de Cooperação Brasil-CERN, o grupo que iniciou com pouco mais de uma dezena de cientistas conta hoje com mais de uma centena de especialistas de diversas áreas, que compõem inclusive equipes internacionais e são respeitados nos países de vanguarda científica. Esses especialistas lideram um número muito maior de estudantes que se dedicam ao estudo da FAE e áreas correlatas, principalmente no que se refere à geração e desenvolvimento de novas tecnologias a partir da pesquisa iniciada pelos principais pesquisadores brasileiros da FAE.

Os experimentos LHCb e CMS apresentaram um desenvolvimento significativo apenas na formação de recursos humanos e pesquisa básica. $O$ desenvolvimento observado nesses experimentos resulta, portanto, das atividades de intercâmbio e colaboração internacional, que este estudo permite inferir, seriam os mesmos caso o Acordo Brasil-CERN não tivesse sido firmado, algo parecido com o que ocorreu no período entre 2000 e 2006, quando não havia um instrumento que legitimasse a cooperação e mesmo assim a atividade dessas equipes brasileiras não cessaram.

Já a equipe brasileira que trabalha no ATLAS conseguiu gerar um desenvolvimento científico e tecnológico substancial por ter contado com o apoio institucional do Governo, que assumiu 
o compromisso de financiar a equipe brasileira para construir um conjunto de circuitos, fato que gerou um amplo desenvolvimento em ciência, tecnologia e inovação. Nesse experimento se observou o ciclo completo da Cooperação Internacional proposto por este trabalho, partindo do estoque de conhecimento, cientistas e equipamentos que permitiram o acesso à pesquisa no CERN, que por sua vez proporcionaram a participação na construção do detector, promovendo o desenvolvimento em C\&T estrutural do setor no Brasil, ampliando a formação de recursos humanos nesta área e levando a pesquisa em C\&T no País a um novo patamar.

Entretanto, a falta de um apoio mais qualificado emperrou esse processo virtuoso percebido no projeto ATLAS, o que leva à constatação de que a Cooperação Internacional em C\&T deve ser tratada no longo prazo, prevendo-se inclusive a continuidade do apoio e a elaboração de estratégias de financiamento correspondentes ao processo do desenvolvimento científico adquirido. Ou seja, se não houver uma decisão de uma política pública voltada para a continuidade e até mesmo ampliação do apoio institucional e financeiro à cooperação BrasilCERN, o País corre o risco de perder os frutos 18 anos de cooperação, sacramentando o atraso brasileiro em C\&T na área. Uma visão estratégica mais sistemática da $\mathrm{Cl}$ como a processo de formulação e gestão das políticas públicas de desenvolvimento científico e tecnológico, tal qual apresentada nesta dissertação, poderia evitar a ruptura do fluxo de investimentos financeiros e institucionais para a participação brasileira no CERN.

Dessa forma, entende-se que Cooperação Internacional em C\&T é elemento fundamental para promover o desenvolvimento científico do País, e deve ser considerada desde a elaboração de políticas públicas de desenvolvimento científico e tecnológico, o acompanhamento de todo o processo, até se alcançar o momento de avaliação dos resultados. Entretanto, ela deve ser tratada estrategicamente, como um passo posterior a experiências de intercâmbio e colaborações internacionais. É preciso prever o ciclo virtuoso da cooperação internacional voltada ao desenvolvimento científico e tecnológico, observando as necessidades crescentes de apoio à construção de estruturas e financiamento para a realização das atividades de P\&D em nível internacional. Da mesma forma, deve-se vislumbrar a interação Universidade-Empresa nesse processo, promovendo a atividade de cientistas em centros de desenvolvimento tecnológicos da indústria nacional, como observado no experimento ATLAS. E, principalmente, deve-se dar maior atenção à Cooperação Internacional com colaborações e iniciativas científicas internacionais, como o CERN, que permite a formação de recursos humanos e o desenvolvimento de atividades em Ciência,Tecnologia e Inovação capazes de tornar o Brasil apto a acompanhar a fronteira do processo de evolução da ciência e tecnologia no mundo.

\section{Referências}

ALVES, Gilvan et al, (2000) O Mundo das Partículas Elementares de Hoje e de Ontem - Rio de Janeiro, Centro Brasileiro de Pesquisas Físicas - CBPF.

ALMEIDA JÚNIOR, Fernando Marroquim Leão de. (2004) Relatórios de atividades no Experimento ATLAS. Universidade Federal do Rio de Janeiro. Rio de Janeiro e Brasília.

AMORIM, Celso L. N. (1994) Perspectiva da Cooperação Internacional. In: MARCOVITCH, Jacques (org.). Cooperação Internacional: Estratégia e Gestão. São Paulo: Editora da Universidade de São Paulo.

BOZEMAN, Barry \& CORLEY, Elizabeth. (2004) Scientists' collaboration strategies: implications for scientific and technical human capital. In: Research Policy, Volume 33, no. 4, ed. Elsevier, Amsterdam - Holanda.

Brasil. Ministério da Ciência e Tecnologia - MCT. (2002) Livro Branco: Ciência, Tecnologia e Inovação. Brasília: Ministério da Ciência e Tecnologia.

BRASIL, CONSELHO NACIONAL DE DESENVOLVIMENTO CIENTÍFICO ETECNOLÓGICO - CNPq. (1990) Convênio de Cooperação entre o Centro Europeu para Pesquisa Nuclear (CERN) e o Conselho Nacional de Desenvolvimento Científico e Tecnológico (CNPq) sobre Cooperação Científica e Técnica em Física de Altas Energias. Brasília.

(2006) Convênio de Cooperação entre o Centro Europeu para Pesquisa Nuclear (CERN) e o Conselho Nacional de Desenvolvimento Científico e Tecnológico (CNPq) sobre Cooperação Científica e Técnica em Física de Altas Energias. Brasília.

CBPF, Centro Brasileiro de Pesquisas Físicas. Relatório ao Ministério da Ciência e Tecnologia - MCT sobre alguns aspectos da Física Brasileira. Disponível em <http://www.cbpf.br/ pdf/RelatorioMCT.pdf>.Acesso em I5 de janeiro de 2007.

CERN Courier. LHCb's Brazilian CARIOCA. International Journal of High Energy Physics. Volume 40, Number 9, Genebra, Suíça, Novembro de 2000. 
CRIBB, André Y. Inovação e difusão: considerações teóricas sobre a mudança tecnológica. Essência Científica, Vol. I, No. I, Pp. I - 12, mar. 2002. Disponível em: <http://www.gifad.org.br/ publicacoes/escient/ec_01010102.htm>.Acesso em 5 de maio 2008.

DUARTE, Rafael P. A Cooperação Internacional Científica e Tecnológica entre o Brasil e o Centro Europeu para Pesquisa Nuclear: contribuições para o desenvolvimento brasileiro. Monografia (Trabalho de conclusão de curso de Graduação em Relações Internacionais). Curso de Relações Internacionais, Universidade Católica e Brasília, Brasília, 2004. Disponível em <http://www.mct.gov.br/upd_blob/I3450.pdf>. Acesso em 24 de abril de 2007.

LOPES, José. (2000)L. Do Átomo Pré-Socrático à Teoria da Relatividade In: CARUSO, F. \& SANTORO,A. Do Átomo Grego à Física de Interações Fundamentais. 2. ed. Rio de Janeiro, CBPF, 240p.

MONTOYAMA, Shozo et al. (2000) 500 Anos de C\&T no Brasil. Suplemento Especial, Fapesp Pesquisa, No. 52.

MORGANTTI, Patrícia A. (2005) O. A Cooperação Científica Brasil - França: o caso do Convênio CNPq/CNRS. Dissertação (Mestrado Profissionalizante em Ciência e Tecnologia) Coordenação de Pós-Graduação em Ciência e Tecnologia Centro de Desenvolvimento Sustentável, UnB.

SÁENZ,T.W. \& SOUZA-PAULA, Maria Carlota. (200I)Desafios Institucionais para o setor de Ciência e Tecnologia: O Sistema Nacional de Ciência e Inovação Tecnológica. In: Parcerias Estratégicas, número 13. Centro de Gestão e Estudos Estratégicos (CGEE).

SALMERON, Roberto. CERN: Uma experiência Científica, Social e Humana. Revista FAPESP, Edição 10, São Paulo - SP, dezembro de 2004, disponível em <http://www.revistapesquisa.fapesp.br/extras/imprimir.php?id=30|4\&bid=|>. Acesso em 13 de dezembro de 2006.

SANTORO, Alberto F.S. \& NOVAES, Sérgio F. Física de Altas Energias: Características e Particularidades da Área. Sociedade Brasileira de Física (SBF). Disponível em <http://www.sbfisica.org.br/comissao_pc/HEPDOC.pdf>. Acesso em 15 de março de 2007.

SANTORO, Alberto F. S. (2002) Participação no Experimento CMS. Carta de Intenção enviada ao Conselho Nacional de Desenvolvimento Científico e Tecnológico - CNPq, Brasília. Importância para a Economia: Para não dizer que não falei de Flores. In: ALVES, Gilvan et al, O Mundo das Partículas Elementares de Hoje e de Ontem - Rio de Janeiro, Centro Brasileiro de Pesquisas Físicas - CBPF, pp. | 3 |- | 47.

The Large Hadron Collider Beauty Experiment. Site principal da colaboração LHCb. Acessado em <http://lhcb.web.cern.ch/ $\mathrm{lhcb} />$ entre agosto de 2003 e maio de 2004.

TROYJO, Marcos P. (2003) Tecnologia \& Diplomacia: desafios da cooperação internacional no campo científico e tecnológico. São Paulo, Editora Aduaneiras.

VELHO, Lea Maria L. S. (200I) Redes regionais de cooperação em C\&T e o Mercosul. In: Parcerias Estratégicas. Ministério da Ciência e Tecnologia (MCT) Brasília, n. I0.

WAGNER, Caroline S.; Brahmakulam, Irene; Jackson, Brian; Wong, Anny; YODA, Tatsuro. Science and Technology Collaboration: Building Capacity in Developing Countries? RAND Corporation, Santa Monica, California, EUA, 200I. Disponível em <http://www.rand.org/pubs/monograph_reports/2005/MRI357.0.pdf >.Acesso em 22 de abril de 2007. 